\title{
Three-Year Course of Cannabis Dependence and Prediction of Persistence
}

\author{
Peggy van der Pol ${ }^{a}$ Nienke Liebregts ${ }^{b}$ Ron de Graaf ${ }^{a}$ Dirk J. Korf ${ }^{b}$ \\ Wim van den Brink ${ }^{c}$ Margriet van Laar ${ }^{\mathrm{a}}$ \\ ${ }^{a}$ Trimbos Institute, Netherlands Institute of Mental Health and Addiction, Utrecht, ${ }^{\text {b } B o n g e r ~ I n s t i t u t e ~ o f ~ C r i m i n o l o g y, ~}$ \\ Law Faculty, University of Amsterdam, Amsterdam, ' Department of Psychiatry, Academic Medical Centre, University of \\ Amsterdam, Amsterdam, The Netherlands
}

\section{Key Words}

Persistent cannabis dependence - Cannabis exposure .

Risk factors · Longitudinal $\cdot$ Course $\cdot$ Symptoms

\begin{abstract}
Aims: To examine the course and the predictors of the persistence of cannabis dependence. Methods: Through cannabis outlets and chain referral, a prospective enriched community cohort of 207 young adults (aged 18-30) with DSMIV cannabis dependence at baseline (T0) was formed and followed-up after 1.5 (T1) and 3 (T2) years. The presence of cannabis dependence, cannabis-related problems, functional impairment and treatment was assessed using the Composite International Diagnostic Interview (CIDI 3.0) and the Sheehan Disability Scale (SDS). Predictors of persistence were lifetime cannabis abuse and dependence symptoms, cannabis use characteristics, distant vulnerability factors (e.g. childhood adversity, family history of psychological/ substance use problems, impulsivity, mental disorders), and proximal stress factors (recent life events, social support). Results: Four groups were distinguished: persistent dependent (DDD: 28.0\%), stable non-persistent (DNN: 40.6\%), late non-persistent (DDN: 17.9\%) and recurrent dependent (DND: 13.5\%). At T2, persisters (DDD) reported significantly more (heavy) cannabis use and cannabis problems than non-persisters (DNN/DDN/DND). Treatment seeking for can-
\end{abstract}

nabis-related problems was rare, even among persisters (15.5\%). The number (OR $=1.23(1.03-1.48)$ ) and type ('role impairment' $\mathrm{OR}=2.85$ (1.11-7.31), 'use despite problems' $\mathrm{OR}=2.34$ (1.15-4.76)) of lifetime cannabis abuse/dependence symptoms were the only independent predictors of persistence with a total explained variance of $8.8 \%$. Conclusions: Persistence of cannabis dependence in the community is low, difficult to predict, and associated with a negative outcome. The substantial proportion of stable non-persisters suggests that screening and monitoring or low-threshold brief interventions may suffice for many non-treatmentseeking cannabis-dependent people. However, those with many lifetime abuse/dependence symptoms may benefit from more intensive interventions.

(c) 2015 S. Karger AG, Basel

\section{Introduction}

Cannabis dependence is the most prevalent illicit substance use disorder worldwide and is associated with serious mental disorders, physical ailments and social impairments [1-4]. A recent global estimate attributed

Sponsor: ZonMW, The Netherlands organisation for health research and development.

\section{KARGER 125}

(c) 2015 S. Karger AG, Base

$1022-6877 / 15 / 0216-0279 \$ 39.50 / 0$

E-Mail karger@karger.com

www.karger.com/ear
Peggy van der Pol

Trimbos Instituut

Da Costakade 45

NL-3521 VA Utrecht (The Netherlands)

E-Mail ppol@ trimbos.nl 
roughly 2 million years lived with disability to cannabis dependence [5]. Still, very little is known about the natural course of cannabis dependence. Two general population studies suggest that most dependent users eventually remit (i.e. no longer fulfil the diagnostic criteria of dependence) $[6,7]$. In a systematic review the aggregated annual remission rate among cannabis-dependent users was estimated at $17 \%$, although definitions and followup periods varied between studies [8]. Given these high 'natural' remission rates, it is important to differentiate those at risk of a persistent course from those with spontaneous recovery. By targeting the available effective treatments of cannabis dependence $[9,10]$ on those unlikely to show spontaneous remission, we can economize the limited intervention budgets.

However, we first need a more detailed understanding of the meaning of remission from cannabis dependence because diagnostic remission from dependence does not necessarily equate to cessation of cannabis use, cannabis use problems or functional impairment, and the related risk of relapse to dependence $[11,12]$. Currently, levels of cannabis use or related problems following a period of cannabis dependence have only been quantified among remitted patients from clinical samples $[9,13,14]$ and results are thus influenced by the treatment itself and the selection of more severe cases typically seen in treatment $[15,16]$. It is therefore important to know more about cannabis use, cannabis use problems and functional impairment of cannabis-dependent individuals in the community who remit from dependence compared to persistent dependent users. However, even large community samples generally do not contain enough subjects with current cannabis dependence to study persistence and remission and the associated changes in cannabis use, cannabis use problems and functional impairment. Therefore, an enriched community sample is needed to study this topic in greater depth.

An efficient use of treatment resources also requires more information on the predictors of persistence. To date, no study has prospectively examined the possible predictors of persistence of cannabis dependence. Swift and colleagues performed a 1 year prospective study, but this study also included heavy users without dependence [17]. In this study, $44 \%$ was dependent at 1-year followup. Although age, years of cannabis use and the total quantity of cannabis use predicted dependence at followup only bivariately, the number of baseline cannabis abuse/dependence symptoms was the only independent and strongest predictor of 'persistence'. The predictive power of individual cannabis abuse and dependence symptoms was not considered, while certain abuse/dependence symptoms (especially impaired control over use') have been shown to be more predictive than others for persistent cannabis use [7], onset of cannabis dependence in frequent users [18] and persistence of alcohol use disorders [19]. Two retrospective studies showed higher remission rates in younger, female, highly educated and employed subjects, in subjects with a later onset of cannabis dependence, a shorter duration of cannabis dependence and in subjects without other mental disorders (conduct disorder (CD), personality disorder, alcohol dependence, cocaine dependence) [20, 21]. However, findings regarding externalizing disorders were somewhat inconsistent: CD increased the probability of remission, whereas antisocial personality was one of the personality disorders that reduced the probability of remission [21]. These studies are, however, constrained by the absence of cannabis exposure measures $[20,21]$ or imprecise estimates such as number of days using cannabis and number of cones per day [17]. Especially among frequent or dependent cannabis users, more detailed measures of exposure, including cannabis dose per joint and THCconcentration, may be better predictors of the course of cannabis dependence $[18,22]$.

Although these prospective persistence and retrospective remission studies provide several leads for potential predictors of a persistent course, evidence is still limited. Therefore, it may be worthwhile to explore additionally the predictors of the onset of dependence, as these could predict an adverse course in general, including persistence of dependence. Cannabis users with coping-oriented reasons to use cannabis have been found to be at a higher risk to develop dependence [18, 23-25]. Similarly, a family history of substance use disorders has been associated with dependence, although in one of the retrospective studies it was not associated with remission [2628]. Moreover, major depression was recently found to predict recurrence of cannabis dependence [11] and both depression and anxiety disorders predicted the onset of dependence [27, 29]. However, contradicting findings have been reported as well $[18,30]$. Current stressful factors increase the risk of cannabis dependence [18,31], but again there is no information on the role of stress factors in the prediction of cannabis dependence persistence. Examples of acute stress factors include recent negative life events and lack of social support [18, 32-34].

The first aim of the current study is to provide an estimate of the 1.5- and 3-year persistence rate of cannabis dependence in young adults from the community and to examine the clinical characteristics of persistent and non- 
persistent subjects in more detail, including cannabis use, cannabis-related problems and functional impairments at follow-ups. The second aim of the study is to investigate predictors of persistent cannabis dependence.

\section{Methods}

\section{Population}

Data of 252 cannabis users meeting criteria for 12-month DSM-IV cannabis dependence were taken from a prospective cohort of 600 frequent cannabis users (eligible when using cannabis $\geq 3$ days per week for the past year; aged 18-30; speaking Dutch fluently). For a detailed description of the study design and the assessment instruments, the reader is referred to van der Pol et al. [35]. Participants were recruited from 27 cannabis outlets (coffee shops, $\mathrm{n}=200$ ) and all participants were asked to bring in a maximum of three frequent cannabis users from their social network. Hence, users who intermittently visited the coffee shops or who bought their cannabis at other outlets and could not be easily enrolled in coffee shops, were 'self-selected' through chain referral $(n=400)$. Although it was impossible to systematically record their willingness to participate, based on our field experience, an estimated $60 \%$ of all people who were asked to participate and fulfilled inclusion criteria were included in this study. Baseline measures (T0, September 2008-April 2009) included a face-to-face interview to assess the presence of 12-month DSM-IV cannabis dependence ( $\geq 3$ dependence symptoms in the past 12 months) and a range of potential predictors of cannabis dependence, including lifetime cannabis abuse and dependence symptoms, cannabis use characteristics, sociodemographics, vulnerability indicators and stress factors [see subsequent paragraphs and: 18]. In addition, there were two face-to-face follow-up interviews assessing the persistence of the DSM-IV diagnosis of cannabis dependence, cannabis use, cannabis problems and functional impairments after 18 months (T1, March-November 2010) and after 36 months (T2, September 2011-March 2012). Participants were asked to provide their own contact details, which were checked and updated every five months, and those of two significant others, to reduce attrition.

\section{Assessments}

Outcome Variables

At all waves, the Composite International Diagnostic Interview (CIDI 3.0) was used to assess the DSM-IV cannabis dependence diagnosis [36]. This diagnosis requires a clustering of three or more of seven symptoms within a 12 -month period. Those who were dependent (i.e. $\geq 3$ dependence symptoms within 12 months) in the period since the previous interview at both $\mathrm{T} 1$ and $\mathrm{T} 2$ were labeled persistent cannabis dependent (DDD). In addition, three non-persistent groups were distinguished: stable non-persistent (i.e. non-dependent at $\mathrm{T} 1$ and $\mathrm{T} 2(\mathrm{DNN})$ ), late non-persistent (i.e. still dependent at T1 but non-dependent at T2 (DDN)) and recurrent dependent (i.e. non-dependent at $\mathrm{T} 1$ but again dependent at T2 (DND)). As such, these non-persistent groups include people with one or two CUD symptoms, labelled 'in partial remission' in DSM-IV.

Persistence of Cannabis Dependence
For each wave, cannabis exposure variables included the number of days using cannabis and the number of joints per cannabis use day in the past 4 weeks. Cannabis use problems included cannabis-related problems in the last 12 months in four different domains of functioning (home, work/school, friendships, social life) rated from 0-10 using the Sheehan Disability Scale (SDS) [37]; ratings that were subsequently dichotomised into $\leq 3 \mathrm{no} / \mathrm{mild}$ problems and $\geq 4$ moderate/severe problems. In addition, the presence of DSM-IV cannabis abuse (irrespective of dependence status) was assessed. Functional impairment in the past four weeks was assessed with a general scale of functioning not specifically related to cannabis dependence: the Short Form-36 Health Survey (SF-36) [38], which includes three subscales (range $0-100$, where 100 represents perfect functioning): emotional role limitations, vitality and social functioning. In addition, number of days lost from work or other activities in the past four weeks was measured with two questions from the WHO Disability Assessment Schedule [39]. Finally, any specialized addiction treatment between $\mathrm{T} 0$ and $\mathrm{T} 2$ was recorded.

\section{Baseline Predictors of Persistent Cannabis Dependence}

Baseline cannabis use was assessed in detail and included four categories of variables. First, variables related to cannabis use disorders (CUD) were assessed with the CIDI 3.0. These included the separate lifetime CUD symptoms (total of 11 symptoms: 4 for cannabis abuse and 7 for cannabis dependence; table 3 ), the total sum of lifetime CUD symptoms and duration of lifetime dependence at baseline (measured as the number of years with three or more cannabis dependence symptoms). Second, variables related to cannabis exposure were assessed, including the age of first cannabis use and cannabis use in the last four weeks (number of cannabis using days, preferred type of cannabis (herbal yes; no), users' estimate of cannabis potency (high; middle; low [40]), number of joints per using day, cannabis dose per joint (1 g/number of joints from one gram [40])). In addition, total cannabis exposure (in grams) in the last four weeks was measured by multiplying the number of days that cannabis was used by the number of joints per day and the estimated dose per joint. Third, the setting of cannabis use was defined by the location (non-selective; home; coffee shop); solitary use or use with others; using at night or (also) in daytime; number of hours 'high' per using day; pauses while smoking a joint (rarely to never; sometimes to always); average intensity of perceived intoxication during cannabis consumption measured on a visual analogue scale ranging from 1 (light buzz) to 10 (very 'high'). Fourth, motives for cannabis use were assessed with the Marijuana Motives Measure (MMM) [41]. The MMM is a 25-item self-report questionnaire with five internally consistent subscales of five items each (subscale range 5-25) measuring enhancement, conformity, expansion, coping and social motives.

Sociodemographic Variables. Age, sex, ethnicity (Western vs. non-Western), educational level (primary or lower secondary; higher secondary; higher professional or university), employment situation (employed; unemployed or unable to work; student) and living arrangement (living alone vs. living with others) were assessed.

Other Substance Use. The (problematic) use of other substances included 12-month alcohol use and alcohol-related problems measured with the Alcohol Use Disorders Identification Test [AUDIT: 42] and a measure of smoking and smoking-related problems in the past four weeks using the Heaviness of Smoking Index [HSI: 43]. Finally, any 12-month use of ecstasy, cocaine or amphetamines was assessed using an ad hoc questionnaire. 
Four Types of Distant Vulnerability Factors. First, lifetime parental history of psychiatric (anxiety; depression; psychosis) or substance use problems (alcohol, cannabis or other drugs) in the biological parents were assessed through self-report by participants. Second, two types of adversity during childhood were evaluated: (i) the presence of one or more of the following childhood 'family adversities' before age 16: parental divorce, parental death and not being brought up by both parents, and (ii) a history of any 'child abuse' before age 16: emotional, psychological, physical, and sexual abuse, using a list of examples including ignorance of one's problems, being subordinated to siblings, being beaten up and being touched or having to touch someone with a perverse intention, respectively [44-47]. Because these experiences of physical abuse may not always occur in isolation and may have an additive effect, the cumulative number of these four types of child abuse was used as the main predictor [48]. Third, the personality characteristic impulsivity was measured with the Dutch version of the Barratt Impulsiveness Scale (BIS-15). This is a 15-item reliable measure of impulsivity, which consists of three subscales: motor, attentional and non-planning impulsivity [49]. Finally, the personal history of mental disorders was assessed with the CIDI and was categorised in three categories of lifetime DSM-IV diagnoses: any mood disorder (major depression, bipolar disorder, dysthymia); any anxiety disorder (social phobia, panic disorder, agoraphobia, generalised anxiety disorder); any externalising disorder (childhood ADHD, conduct disorder). Lifetime psychotic symptoms such as hallucinations and delusions (yes; no) were measured with a selection of six items of the psychosis section of CIDI $1.1[35]$.

Proximal Stress Factors. Negative and positive recent life events were included as two count variables. Major negative recent life events that occurred in the past 12 months were assessed with Brugha's List of Threatening Experiences [50]. In addition, we included positive equivalents related to recent events about friendships, relationships, graduation and work in the previous 12 months [18]. Finally, perceived lack of current social support was assessed with two questions about being able to rely on ones social network for emotional and for practical help.

\section{Statistical Analysis}

Persistence of Cannabis Dependence

In addition to the strictly defined persistence at both follow-up points (DDD), persistence rate at T1 (DDD or DDN) and dependence prevalence at $\mathrm{T} 2$ irrespective of $\mathrm{T} 1$ dependence status (DDD or DND) were reported. Average T1 and T2 cannabis use, cannabis use problems, and functional impairment are reported for the four dependence trajectories. Differences between persistent dependence and the three non-persistent trajectories were tested using bivariate multinomial logistic regression analyses, which allow the analysis of nominal dependent variables, which in this case are the dependence trajectories, in which persistent dependence was the reference group.

\section{Predictors of Persistence}

The predictive value of each baseline lifetime CUD symptom was assessed bivariately comparing persistent cannabis dependence (DDD) with non-persistent cannabis dependence (DNN, DDN, DND) in bivariate logistic regression analyses. In addition, the independent predictive value of these symptoms was assessed by simultaneous inclusion of all lifetime symptoms in a multivari- able logistic regression analysis. Odds ratios (ORs) and 95\% confidence intervals (95\% CIs) are reported.

Similarly, baseline cannabis use characteristics (exposure, setting, motives), the sum of lifetime CUD symptoms and the other potential predictors were compared between persisters and non-persisters. Again, these variables were first assessed bivariately. Then, to identify the independent contribution of predictors of cannabis-dependent persistence, all bivariate predictors significant at the $\mathrm{p} \leq 0.10$ level were entered into a multivariable logistic regression [see: 51]. Only variables significant at the 5\% level in the multivariable model are considered to be independent predictors. An overall estimate of the predictive power of all predictors together is provided by McFadden's pseudo $\mathrm{R}^{2}$. The total number of the lifetime CUD symptoms is expected to be a strong predictor of the course of cannabis dependence [7, $18,19]$, which may overshadow all other potential clinically important predictors. Therefore, the multivariable model was first tested with, and then without the lifetime number of CUD symptoms in the model.

\section{Results}

\section{Persistence of Cannabis Dependence}

The final sample included 207 participants (53 recruited from coffee shops and 154 through chain referral) with complete data at both $\mathrm{T} 1(\mathrm{n}=222 / 252,88.1 \%)$ and $\mathrm{T} 2$ (207/252, 82.1\%). Attrition was independently predicted by the interviewer and recruitment type (coffee shop versus chain referral) and by non-Western ethnicity.

At the first follow-up, 45.9\% (95/207) was still dependent and only $28.0 \%(n=58 / 207)$ of dependent users was persistently cannabis dependent at both follow-up measurements, fulfilling the strict definition of persistence (DDD). The other trajectories were: 84 stable non-persisters (DNN, 40.6\%), 37 late non-persisters (DDN, $17.9 \%$ ) and 28 recurrent dependent subjects (DND, $13.5 \%)$.

Cannabis use, cannabis problems and functional impairment at each wave are shown per trajectory in table 1 . Generally, the three non-persistent groups scored better than persisters. Yet regarding cannabis use problems, DDD did not differ statistically significantly from DDN at T1 and from DND at T2. Hence, cannabis problems mainly reflected the dependence status at the specific wave.

Overall, cannabis use decreased after baseline. After three years (T2), non-dependent subjects consumed significantly less cannabis than persistent cannabis-dependent subjects, but they still consumed cannabis on 10.9 $(\mathrm{DDN})$ to $14.6(\mathrm{DNN})$ days per month and $1.4(\mathrm{DDN})$ to 1.8 (DNN) joints per using day. Even in the stable nonpersisters $(\mathrm{DNN})$ who showed the least cannabis prob- 


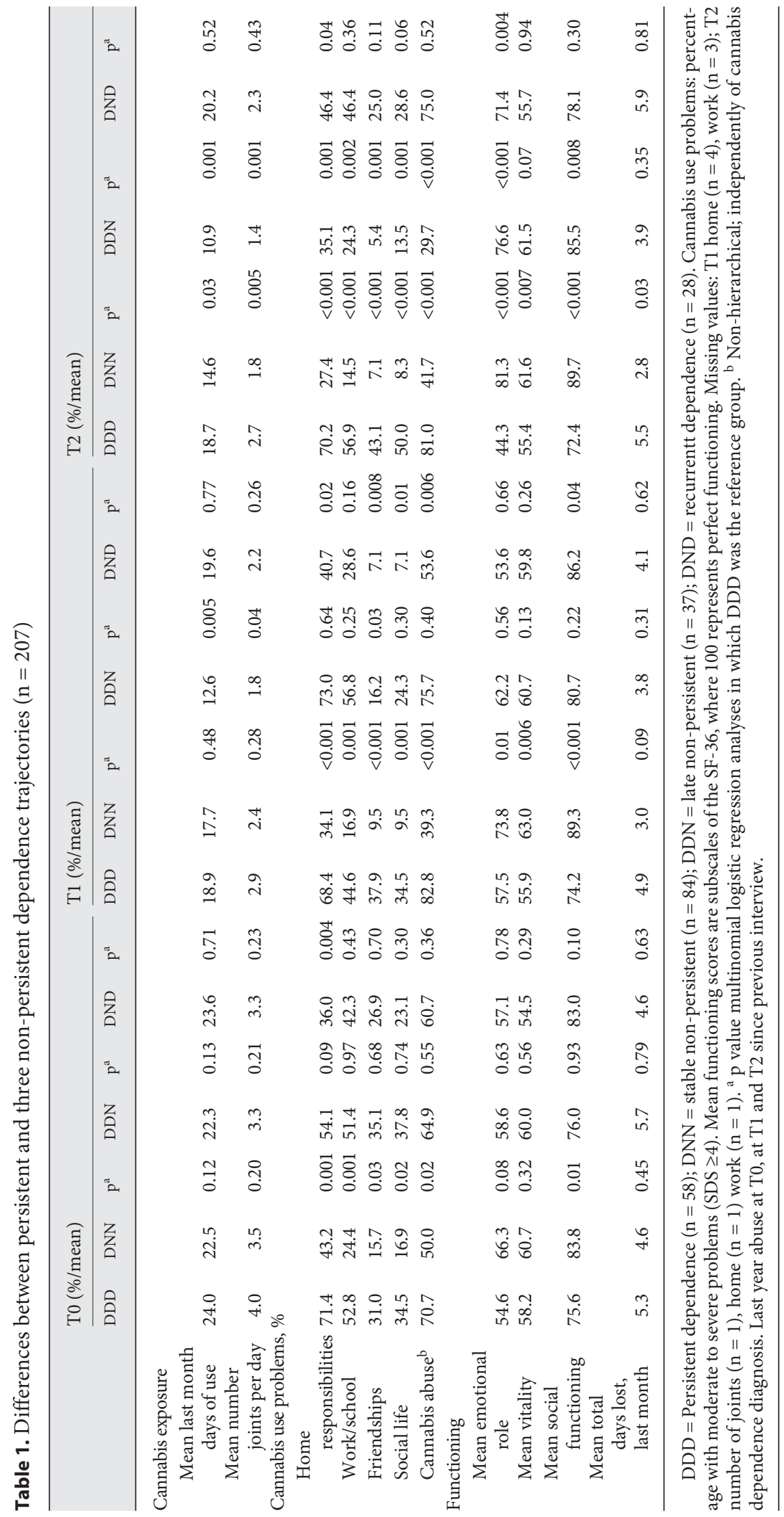


Table 2. Lifetime DSM-IV cannabis abuse and dependence symptoms at baseline predicting persistent dependence (DDD)

\begin{tabular}{|c|c|c|c|c|c|c|c|c|}
\hline & \multicolumn{4}{|c|}{$\begin{array}{l}\text { Persistent dependence } \\
\text { (DDD) }\end{array}$} & \multicolumn{2}{|c|}{$\begin{array}{l}\text { Bivariate } \\
\text { logistic regression }\end{array}$} & \multicolumn{2}{|c|}{$\begin{array}{l}\text { Multivariable } \\
\text { logistic regression }\end{array}$} \\
\hline & $\mathrm{n}$ & $\%$ & $\mathrm{n}$ & $\%$ & OR & $95 \%$ CI & OR & $95 \% \mathrm{CI}$ \\
\hline \multicolumn{9}{|l|}{ Abuse } \\
\hline Role impairment & 96 & 64.4 & 50 & 86.2 & $3.45^{* *}$ & $1.52-7.82$ & $2.85^{*}$ & $1.11-7.31$ \\
\hline Hazardous use & 75 & 50.3 & 31 & 53.5 & 1.13 & $0.62-2.08$ & 0.89 & $0.44-1.78$ \\
\hline Legal problems & 5 & 3.4 & 4 & 6.9 & 2.13 & $0.55-8.24$ & 1.24 & $0.28-5.49$ \\
\hline Social problems & 48 & 32.2 & 25 & 43.1 & 1.59 & $0.85-2.97$ & 0.90 & $0.44-1.87$ \\
\hline \multicolumn{9}{|l|}{ Dependence } \\
\hline Tolerance & 107 & 71.8 & 48 & 82.8 & 1.88 & $0.87-4.07$ & 1.87 & $0.83-4.18$ \\
\hline Withdrawal & 85 & 57.1 & 32 & 55.2 & 0.93 & $0.50-1.71$ & 0.76 & $0.39-1.49$ \\
\hline Larger/longer ${ }^{\mathrm{a}}$ & 147 & 98.7 & 57 & 98.3 & 0.39 & $0.02-6.30$ & 0.24 & $0.01-4.88$ \\
\hline Impaired control over use & 116 & 77.9 & 44 & 75.9 & 0.89 & $0.44-1.83$ & 0.88 & $0.40-1.94$ \\
\hline Much time spent & 88 & 59.1 & 43 & 74.1 & $1.99^{*}$ & $1.01-3.89$ & 1.69 & $0.80-3.56$ \\
\hline Reduced activities & 76 & 51.0 & 38 & 65.5 & 1.82 & $0.97-3.43$ & 1.20 & $0.59-2.45$ \\
\hline \multicolumn{9}{|l|}{ Use despite } \\
\hline problems & 43 & 28.9 & 29 & 50.0 & $2.47^{* *}$ & $1.32-4.60$ & $2.34^{*}$ & $1.15-4.76$ \\
\hline
\end{tabular}

${ }^{*} \mathrm{p}<0.05,{ }^{* *} \mathrm{p}<0.01 . \mathrm{OR}=$ Odds ratio; $\mathrm{CI}=$ confidence interval. Bivariate/multivariable logistic regression compared persistent cannabis dependence (DDD $\mathrm{n}=58$ ) with non-persistent cannabis dependence (DNN stable non-persisters, DDN late non-persisters, and DND recurrent dependent $\mathrm{n}=149$ ) being the reference group. Multivariable logistic regression included all DSM-IV abuse/dependence items in the table. ${ }^{\text {a }}$ Missing values: larger longer $(n=1)$.

lems at every wave, about one third had moderate-tosevere cannabis-related problems with home responsibilities. Persisters showed an increase between T0 and T2 in problems in friendships (from 31.0 to $43.1 \%$ ) and social life (from 34.5 to $50.0 \%$ ), while only one in ten stable non-persisters (DNN) reported cannabis-related problems in friendships and social life at follow-up (ranging between 7.1 and 9.5\%), showing that these problems were relatively rare in the absence of dependence. For functioning, these patterns were less distinctive: functioning of persisters was rather stable over time, whereas non-persisters (DDN and DNN) reported better functioning at $\mathrm{T} 2$.

Finally, despite the presence of many cannabis use problems, treatment seeking in specialised addiction treatment services between T0 and T2 was uncommon. Persisters (DDD) most frequently reported treatment ( $\mathrm{n}=9 ; 15.5 \%)$, but the frequency did not differ significantly from DDN subjects $(\mathrm{n}=4 ; 10.8 \%, \mathrm{p}=0.52)$ and DND subjects $(\mathrm{n}=1 ; 3.6 \%, \mathrm{p}=0.14)$. However, stable non-persisters (DNN) reported statistically significantly less treatment than persisters $(\mathrm{DDD})(\mathrm{n}=3 ; 3.6 \%$ vs. $\mathrm{n}=$ $9 ; 15.5 \%, \mathrm{p}=0.02)$.

\section{Predictors of Persistent Dependence}

Bivariate and multivariable logistic regressions were performed to identify the specific baseline lifetime CUD symptoms that predict persistency. The abuse symptom 'role impairment' (table 2, OR $=3.45,95 \% \mathrm{CI}=1.52-$ 7.82) and the dependence symptoms 'much time spent' $(\mathrm{OR}=1.99,95 \% \mathrm{CI}=1.01-3.89)$ and 'use despite problems' $(\mathrm{OR}=2.47,95 \% \mathrm{CI}=1.32-4.60)$ were bivariate predictors of persistency, but 'much time spent' did not remain statistically significant in the multivariable model.

Of the cannabis-related variables shown in table 3 , only the total number of lifetime CUD symptoms (OR = $1.31,95 \% \mathrm{CI}=1.11-1.55)$ and coping motives to use cannabis $(\mathrm{OR}=1.11,95 \% \mathrm{CI}=1.03-1.20)$ significantly predicted persistence. Also, the vulnerability factors lifetime anxiety disorder $(\mathrm{OR}=2.03,95 \% \mathrm{CI}=1.01-4.07)$ and any psychosis symptom $(\mathrm{OR}=2.45,95 \% \mathrm{CI}=1.03-5.84)$ significantly predicted a persistent course. In addition to these variables, the number of hours 'high' and social motives to use cannabis were included in the multivariable model as they were marginally significant $(\mathrm{p}<$ 0.10 ) associated with persistence. In the multivariable model, the total number of lifetime CUD symptoms was the only independent predictor of cannabis-dependent 
Table 3. Bivariate baseline predictors of persistent dependence (DDD)

\begin{tabular}{|c|c|c|c|c|c|c|}
\hline 3-year persistent dependence & $\begin{array}{l}\text { No } \\
\% / \text { mean }\end{array}$ & $\mathrm{SD}$ & $\begin{array}{l}\text { Yes } \\
\% / \text { mean }\end{array}$ & $\mathrm{SD}$ & OR & $95 \% \mathrm{CI}$ \\
\hline \multicolumn{7}{|l|}{ Cannabis } \\
\hline Mean dependent years & 3.1 & $(2.1)$ & 3.4 & $(2.5)$ & 1.07 & $0.93-1.22$ \\
\hline \multicolumn{7}{|l|}{ Exposure } \\
\hline Mean age of onset first use & 13.8 & $(2.1)$ & 14.4 & $(2.7)$ & 1.13 & $0.97-1.30$ \\
\hline Preference for herbal cannabis & 101 & 67.8 & 42 & 72.4 & 1.25 & $0.64-2.44$ \\
\hline \multicolumn{7}{|l|}{ Preferred perceived potency } \\
\hline Low & 10 & 6.8 & 5 & 8.6 & 1.00 & $1.00-1.00$ \\
\hline Middle & 45 & 30.4 & 15 & 25.9 & 0.67 & $0.20-2.26$ \\
\hline High & 93 & 62.8 & 38 & 65.5 & 0.82 & $0.26-2.55$ \\
\hline Mean number of joints per day & 3.4 & $(2.2)$ & 4.0 & $(2.7)$ & 1.11 & $0.98-1.25$ \\
\hline \multicolumn{7}{|l|}{ Setting } \\
\hline Non-selective & 25 & 16.8 & 12 & 20.7 & 1.00 & $1.00-1.00$ \\
\hline Home settings & 109 & 73.2 & 41 & 70.7 & 0.78 & $0.36-1.70$ \\
\hline Coffee shops & 15 & 10.1 & 5 & 8.6 & 0.69 & $0.20-2.36$ \\
\hline Solitary use & 36 & 24.2 & 20 & 34.5 & 1.65 & $0.85-3.19$ \\
\hline Using at night (also) in daytime & 52 & 34.9 & 24 & 41.4 & 1.32 & $0.71-2.45$ \\
\hline Hours per day 'high' & 5.5 & $(3.7)$ & 6.6 & $(4.0)$ & $1.07^{+}$ & $1.00-1.16$ \\
\hline No pauses while smoking joint & 68 & 45.6 & 27 & 46.6 & 1.04 & $0.56-1.91$ \\
\hline Mean level of intoxication & 6.3 & $(1.6)$ & 6.1 & $(1.6)$ & 0.91 & $0.75-1.11$ \\
\hline \multicolumn{7}{|l|}{ Motives } \\
\hline Mean enhancement & 15.5 & $(3.3)$ & 16.0 & $(3.2)$ & 1.04 & $0.95-1.15$ \\
\hline Mean conformity & 5.7 & $(1.1)$ & 5.9 & $(2.1)$ & 1.10 & $0.90-1.34$ \\
\hline Mean expansion & 9.8 & $(4.9)$ & 10.6 & $(4.9)$ & 1.03 & $0.97-1.10$ \\
\hline Primary/lower secondary & 36 & 24.2 & 16 & 27.6 & 1.00 & $1.00-1.00$ \\
\hline Higher secondary & 58 & 38.9 & 15 & 25.9 & 0.58 & $0.26-1.32$ \\
\hline Higher professional & 55 & 36.9 & 27 & 46.6 & 1.10 & $0.52-2.33$ \\
\hline \multicolumn{7}{|l|}{ Employment } \\
\hline Employed & 56 & 37.6 & 16 & 27.6 & 1.00 & $1.00-1.00$ \\
\hline Student & 69 & 46.3 & 32 & 55.2 & 1.62 & $0.81-3.26$ \\
\hline Unemployed/unable to work & 24 & 16.1 & 10 & 17.2 & 1.46 & $0.58-3.67$ \\
\hline Living alone (vs. with others) & 28 & 18.8 & 11 & 19.0 & 1.01 & $0.47-2.19$ \\
\hline \multicolumn{7}{|l|}{ Other substances } \\
\hline Mean alcohol (AUDIT) score & 9.2 & $(5.2)$ & 10.1 & $(5.8)$ & 1.03 & $0.97-1.09$ \\
\hline Mean smoking score (HSI) & 1.4 & $(1.5)$ & 1.5 & $(1.6)$ & 1.04 & $0.86-1.27$ \\
\hline Any 12 -month illicit substance use & 71 & 47.7 & 24 & 41.4 & 0.78 & $0.42-1.43$ \\
\hline \multicolumn{7}{|l|}{ Vulnerability } \\
\hline Parental psychological problems & 58 & 38.9 & 29 & 50.0 & 1.57 & $0.85-2.89$ \\
\hline Parental substance use problems & 53 & 35.6 & 22 & 37.9 & 1.11 & $0.59-2.07$ \\
\hline \multicolumn{7}{|l|}{ Childhood } \\
\hline Family adversity & 70 & 47.0 & 27 & 46.6 & 0.98 & $0.54-1.81$ \\
\hline Mean number of child abuse & 1.2 & $(1.2)$ & 1.2 & $(1.3)$ & 1.01 & $0.79-1.28$ \\
\hline
\end{tabular}


Table 3. (continued)

\begin{tabular}{|c|c|c|c|c|c|c|}
\hline 3-year persistent dependence & $\begin{array}{l}\text { No } \\
\% / \text { mean }\end{array}$ & SD & $\begin{array}{l}\text { Yes } \\
\% / \text { mean }\end{array}$ & SD & OR & $95 \%$ CI \\
\hline \multicolumn{7}{|l|}{ Impulsivity } \\
\hline Attentional impulsivity & 11.2 & $(2.6)$ & 11.1 & $(2.4)$ & 0.99 & $0.88-1.11$ \\
\hline Nonplanning & 12.6 & $(2.7)$ & 13.0 & $(2.7)$ & 1.07 & $0.95-1.19$ \\
\hline Any lifetime mood disorder & 37 & 24.8 & 19 & 32.8 & 1.47 & $0.76-2.86$ \\
\hline Any lifetime externalising disorder & 100 & 37.1 & 33 & 56.9 & 0.65 & $0.35-1.20$ \\
\hline Any lifetime psychosis symptom & 13 & 8.7 & 11 & 19.0 & $2.45^{*}$ & $1.03-5.84$ \\
\hline \multicolumn{7}{|l|}{ Stress } \\
\hline Mean number recent positive events & 2.2 & $(1.1)$ & 2.3 & $(0.9)$ & 1.10 & $0.82-1.48$ \\
\hline Mean number recent negative events & 3.4 & $(2.0)$ & 3.6 & $(1.9)$ & 1.06 & $0.90-1.23$ \\
\hline Emotional support below expectations & 48 & 32.2 & 20 & 34.5 & 1.11 & $0.58-2.10$ \\
\hline
\end{tabular}

Table 4. Independent baseline predictors of persistent dependence: multivariable model including (1) and excluding total number lifetime cannabis abuse and dependence (CUD) symptoms (2)

\begin{tabular}{|c|c|c|c|c|}
\hline & \multicolumn{2}{|c|}{ Model 1 including CUD } & \multicolumn{2}{|c|}{ Model 2 excluding CUD } \\
\hline Hours per day 'high' & 1.07 & $0.98-1.16$ & 1.07 & $0.99-1.16$ \\
\hline Mean coping motive & 1.03 & $0.95-1.12$ & 1.05 & $0.97-1.15$ \\
\hline Mean social motive & 1.07 & $0.98-1.16$ & 1.06 & $0.98-1.15$ \\
\hline
\end{tabular}

$* \mathrm{p}<0.05 .-=$ Not included in the model; CUD = cannabis use disorder. Model 1: multivariable logistic model predicting persistence of cannabis dependence (DDD $\mathrm{n}=58$ ) compared with non-persistent cannabis dependence (DNN stable non-persisters, DDN late nonpersisters, and DND recurrent dependent $n=149)$ being the reference group, with all variables in the model (pseudo $\left.\mathrm{R}^{2}=8.8 \%\right)$. Model 2: excludes the number of dependence and abuse symptoms (pseudo $\left.\mathrm{R}^{2}=6.7 \%\right)(\mathrm{n}=206$ as $\mathrm{n}=1$ missing hours 'high').

persistence (table $4, \mathrm{OR}=1.23,95 \% \mathrm{CI}=1.03-1.48$, pseudo $\mathrm{R}^{2}$ Model $1=8.8 \%$ ). When the total number of lifetime CUD symptoms was excluded from this model, the other variables still did not reach significance in the multivariable model (pseudo $\mathrm{R}^{2}$ Model $2=6.7 \%$ ). Although coping motives have consistently been associated with dependence and have been found to mediate associations with internalising disorders, no interaction ( $\mathrm{OR}=0.97,95 \%$ $\mathrm{CI}=0.82-1.19)$ was found in post-hoc analyses $[18,25$, $41,52-55]$.
To test the robustness of our findings, a series of sensitivity analyses were performed (data available on request). Predictors of early remission (DDD + DDN vs. DNN + DND) and remission at three-year follow-up (DDD + DND vs. DDN + DNN) were assessed (e.g. $[7,19])$, with generally similar results. Also, stable trajectories DDD and DNN were compared, because measurement error in the dependence diagnosis may dilute findings, and latent Markov models recently showed that measurement error of the CIDI diagnosis of dependence is likely to be consid- 
erable [18]. Stable trajectories like DDD and DNN are less likely to be affected by diagnostic measurement error, but the results were similar to those including all four groups.

\section{Discussion}

To our knowledge, this is the first study that has explored the course of cannabis dependence and predictors for persistence in a prospective community cohort of young adults. Dependence persisted in a minority $(28.0 \%)$ and was mainly predicted by the number of lifetime abuse/dependence symptoms. Overall, cannabis use decreased during the three-year follow-up; yet subjects in the non-persistent trajectories were neither abstinent nor free from cannabis-related problems. Together with the low cannabis treatment rates, this emphasises the importance of targeted treatments.

\section{Persistence of Cannabis Dependence}

Only $28.0 \%$ fulfilled the criteria for cannabis dependence at both assessments within a three-year follow-up period (DDD); $40.6 \%$ were stable remitters (DNN) who outperformed DDD on all course indices. This raises a doubt whether a chronic or progressive course is the most typical outcome of cannabis dependence. Although cannabis exposure decreased over time, most non-persisters continued their (heavy) cannabis use and a considerable proportion had persistent cannabis-related problems.

In the remaining groups of non-persisters, 13.5\% moved in and out of cannabis dependence (recurrent dependent subjects: DND), underlining the dynamic course of cannabis dependence. More specifically, while cannabis-related problems in the DND group were resolved considerably at $\mathrm{T} 1$, their cannabis use and functioning were not. One may argue that this marks their increased risk for the following relapse. The importance of functional impairment is underlined by our recent finding that functional impairment was the strongest reason to seek treatment for patients in addiction care, while in the current sample, one of the main self-reported barriers to seek treatment was thinking that treatment was not needed [15], in line with a previous study among frequent cannabis users [56]. This may also explain the low treatment seeking rates between $\mathrm{T} 0$ and $\mathrm{T} 2$.

\section{Predictors of Persistent Dependence}

The two cannabis abuse and dependence symptoms that relate to cannabis-related problems emerged as the ones that were most strongly (and independently) associ- ated with persistence: 'role impairment' $(\mathrm{OR}=2.85)$ and 'use despite problems' $(\mathrm{OR}=2.34)$; a finding consistent with previous findings regarding the persistence of alcohol use disorder [19]. In contrast, 'impaired control over use' was previously found to be the strongest predictor of persistent cannabis use and the onset of dependence [7, 18]. Thus, different predictive symptoms for different phases in the onset and course of cannabis use disorders emerged. This is important for differential targeting of prevention and treatment.

Also the total number of lifetime CUD symptoms predicted persistent cannabis dependence $(\mathrm{OR}=1.23)$. Consistent with the study by Swift et al. [17], this was the only other independent predictor. Coping motives, lifetime anxiety disorder and any psychosis symptom were bivariate predictors, but did not add significantly to the predictive value of the total number of lifetime CUD symptoms (and coping motives interacted neither with anxiety nor with psychosis symptoms). However, these factors may still be important for both further research and for clinical practice.

Importantly, cannabis exposure was not a predictor of persistence in the current study, suggesting there is no, or only a very limited, role for cannabis exposure in the persistence of cannabis dependence. This is contradicting the previous findings, which show that the number of cones per day bivariately (not independently) predicted cannabis dependence severity at 1-year follow-up [17]. The argument that our self-reported measures of cannabis exposure were not good or sensitive enough to predict the course of dependence seems unjustified. First, this is because we assessed cannabis exposure in great detail, including cannabis use frequency, joints per using day, dose per joint, estimated cannabis potency and type of preferred cannabis. Although we recently showed that validity of self-reported cannabis dose and potency are indeed modest, the average dose per joint could be estimated accurately at the group level [40]. Second, self-reported exposure measures were sensitive enough to detect differences between dependence trajectories in cannabis exposure at follow-up. Therefore, the difference between our findings and those of Swift et al. are more likely to result from the fact that their study population was more heterogeneous including both dependent and heavy nondependent users, or by their use of the (more sensitive) dimensional outcome measure 'dependence severity'. However, the suggestion that our population of dependent cannabis users was too homogeneous to identify cannabis use (or other) predictors is difficult to reconcile with the considerable differences in cannabis use, canna- 
bis use problems and dependence we found over the course of the study. We therefore feel that there must be factors other than cannabis use and characteristics of cannabis dependence that determine the course of cannabis dependence. Potential candidates for the prediction of the course of cannabis dependence include genetic vulnerability, gene-environment interactions, gene expression and endophenotypic characteristics [57-60]. However, in the current study (large sample, many predictors from different domains, excellent follow-up rate) we were not able to identify more independent predictors of persistence: a long list of potential predictors, assessed with adequate instruments, explained only a small proportion of the variance in the 3-year course of cannabis dependence (pseudo $\mathrm{R}^{2}=8.8 \%$ ). Also, the sensitivity analyses using alternative outcome definitions did not alter the results. So, the assessment of dependence severity rather than using dichotomous diagnoses may possibly improve sensitivity [17]. Altogether, neither our definition of persistence nor the effect of measurement error in the outcome is sufficient explanations for our lack of predictive power. It therefore seems that our findings mainly illustrate the complexity of the prediction of the course of cannabis dependence. Possibly, the complicated process of cannabis dependence remission and persistence cannot be captured with static baseline predictors. Rather, given the dynamic nature of cannabis dependence, changes over time (time dependent predictors or covariates) are needed to predict the development of dependence, thus eliminating between subject variability, improving the reliability of (cannabis exposure) measures. Accordingly, future studies may consider a life course approach linking changes in dependence status to changes in cannabis use and other environmental changes (e.g. life events), or experience sampling methods $[29,61,62]$. This is supported by a qualitative study among a subsample of CanDep: according to the users themselves, changes in cannabis use such as (temporary) increases or decreases are associated with life events, leisure time activities, and social relationships and similar associations with transitions in cannabis dependence status were observed by the authors $[63,64]$.

\section{Methodological Considerations}

The results of the study should be interpreted with taking some limitations into account. First, it should be noted that an enriched community sample was used. While representativeness for cannabis-dependent persons in the general population cannot be determined, this does not necessarily mean that it is a seriously biased sample. After all, most frequent cannabis users in the Netherlands do visit coffee shops and this is why coffee shops are appropriate recruitment sites. Moreover, readiness to participate in the study was high. Second, almost $18 \%$ of the subjects dropped out during the study. This may have introduced bias. However, attrition was mainly associated with methodological issues (reviewer, recruitment type) and with non-Western ethnicity. The methodological predictors of attrition are not very likely to have created bias, but ethnicity could have done so. However, ethnicity was not associated with persistence and therefore, it is unlikely that attrition has created biased results. Third, in this first exploration of the course of cannabis dependence in the general (non-treatment seeking) population, potential confounders were not considered. These issues are mainly important when interpreting descriptive cross-sectional comparisons (table 1) and the point estimates of the course of dependence, as the potential effect of sample characteristics on longitudinal relationships (predictors) is generally thought to be smaller and predictors of persistence were tested multivariably. Finally, we used a rather strict definition of persistence: that is, fulfilling criteria for DSM-IV cannabis dependence (at least 3 symptoms within a 12-month period). Nonetheless, the current study shows a lower 3-year cannabis-dependent persistence (28\%) than previous population studies using the same definition [6, 19]. Other studies have used different definitions (e.g. presence of any CUD symptoms $[20,21]$ or continued cannabis use [7]) and different follow-up period and therefore direct comparison between studies is hardly possible. However, significant differences in the course of cannabis use and cannabis-related problems and functioning between persisters and stable remitters (DNN) seem to indicate that our definition of persistence is appropriate.

\section{Conclusion}

First, less than a third of all dependent users were persistently dependent for three years. Second, persistence is mainly predicted by the number of cannabis abuse/dependence symptoms and particularly by those symptoms related to problems ('role impairment' and 'use despite problems'). Additionally, coping motives for cannabis use and lifetime anxiety disorder or psychosis symptoms may help identify those at risk for a persistent course. Unfortunately, the overall predictive power is limited; thus, further efforts to identify clinically useful predictors are warranted, to develop targeted interventions in this population with a low treatment rate. Given the dynamic nature of cannabis dependence with frequent remissions 
and relapses, it should be considered that it may be most appropriate to screen and monitor users fulfilling criteria for cannabis dependence who do not seek treatment, possibly combined with brief interventions directed at reduction of cannabis use and improvement of cannabis-related problems. Even though the minority that suffered from a persistent course may benefit from immediate intensive treatment, thus far, a chronic course seems difficult to predict. Standard implementation of screening and monitoring may at least result in the identification of persisters in due time and brief interventions may help prevent persistence, or recurrence or relapse in non-persisters with ongoing cannabis use and cannabis-related problems. In addition, new low threshold interventions can be developed to attract more (persistent) dependent cannabis users $[65,66]$. A better understanding of facilitators and barriers to seek treatment may contribute to this goal $[15,56]$. Finally, it should be noted that this study took place among (mostly) non-treatment-seeking, cannabis-dependent people from coffee shops and via chain referral. Of course, people presenting for cannabis dependence treatment should always be offered appropriate care.

\section{Disclosure Statement}

None declared.

\section{References}

1 Conway KP, Compton W, Stinson FS, Grant BF: Lifetime comorbidity of DSM-IV mood and anxiety disorders and specific drug use disorders: results from the national epidemiologic survey on alcohol and related conditions. J Clin Psychiatry 2006;67:247-257.

-2 Stinson FS, Ruan WJ, Pickering R, Grant BF: Cannabis use disorders in the USA: prevalence, correlates and co-morbidity. Psychol Med 2006;36:1447-1460.

-3 UNODC: World Drug Report: 2010. Vienna, UNODC, 2010.

4 Degenhardt L, Hall W: Extent of illicit drug use and dependence, and their contribution to the global burden of disease. Lancet 2012; 379:55-70.

5 Degenhardt L, Ferrari AJ, Calabria B, Hall WD, Norman RE, McGrath J, Flaxman AD, Engell RE, Freedman GD, Whiteford HA, Vos T: The global epidemiology and contribution of cannabis use and dependence to the global burden of disease: results from the GBD 2010 study. PLoS One 2013;8:e76635.

6 Newcomb MD, Galaif ER, Locke TF: Substance use diagnoses within a community sample of adults: distinction, comorbidity, and progression over-time. Prof Psychol Res Pract 2001;32:239-247.

7 Perkonigg A, Goodwin RD, Fiedler A, Behrendt S, Beesdo K, Lieb R, Wittchen HU: The natural course of cannabis use, abuse and dependence during the first decades of life. Addiction 2008; 103:439-449; discussion 450451.

8 Calabria B, Degenhardt L, Briegleb C, Vos T, Hall W, Lynskey M, Callaghan B, Rana U, McLaren J: Systematic review of prospective studies investigating 'remission' from amphetamine, cannabis, cocaine or opioid dependence. Addict Behav 2010;35:741-749.

-9 Denis C, Lavie E, Fatseas M, Auriacombe M: Psychotherapeutic interventions for cannabis abuse and/or dependence in outpatient set- tings. Cochrane Database Syst Rev 2006; 3:CD005336.

10 Danovitch I, Gorelick DA: State of the art treatments for cannabis dependence. Psychiatr Clin North Am 2012;35:309-326.

11 Flórez-Salamanca L, Secades-Villa R, Budney AJ, Garcia-Rodriguez O, Wang S, Blanco C: Probability and predictors of cannabis use disorders relapse: results of the national epidemiologic survey on alcohol and related conditions (NESARC). Drug Alcohol Depend 2013;132:127-133.

12 Rubio JM, Olfson M, Villegas L, Perez-Fuentes G, Wang S, Blanco C: Quality of life following remission of mental disorders: findings from the national epidemiologic survey on alcohol and related conditions. J Clin Psychiatry 2013;74:e445-e450.

13 Arendt M, Rosenberg R, Foldager L, Perto G, Munk-Jorgensen P: Psychopathology among cannabis-dependent treatment seekers and association with later substance abuse treatment. J Subst Abuse Treat 2007;32:113-119.

14 Chen KW, Banducci AN, Guller L, Macatee RJ, Lavelle A, Daughters SB, Lejuez CW: An examination of psychiatric comorbidities as a function of gender and substance type within an inpatient substance use treatment program. Drug Alcohol Depend 2011;118:92-99.

15 Van der Pol P, Liebregts N, de Graaf R, Korf DJ, Van den Brink W, van Laar M: Facilitators and barriers in treatment seeking for cannabis dependence. Drug Alcohol Depend 2013; 133:776-780.

16 Grella CE, Stein JA: Remission from substance dependence: differences between individuals in a general population longitudinal survey who do and do not seek help. Drug Alcohol Depend 2013;133:146-153.

17 Swift W, Hall W, Copeland J: One year follow-up of cannabis dependence among longterm users in Sydney, Australia. Drug Alcohol Depend 2000;59:309-318.
8 van der Pol P, Liebregts N, De Graaf R, Korf DJ, van den Brink W, van Laar M: Predicting the transition from frequent cannabis use to cannabis dependence: a three-year prospective study. Drug Alcohol Depend 2013;133: 352-359.

19 de Bruijn C, van den Brink W, de Graaf R, Vollebergh WA: Alcohol abuse and dependence criteria as predictors of a chronic course of alcohol use disorders in the general population. Alcohol 2005;40:441-446.

20 Gilder DA, Lau P, Corey L, Ehlers CL: Factors associated with remission from cannabis dependence in southwest California Indians. J Addict Dis 2007;26:23-30.

21 Lopez-Quintero C, Hasin DS, de Los Cobos JP, Pines A, Wang S, Grant BF, Blanco C: Probability and predictors of remission from life-time nicotine, alcohol, cannabis or cocaine dependence: results from the national epidemiologic survey on alcohol and related conditions. Addiction 2011;106:657-669.

22 Temple EC, Brown RF, Hine DW: The 'grass ceiling': limitations in the literature hinder our understanding of cannabis use and its consequences. Addiction 2011;106:238-244.

23 Johnson K, Mullin JL, Marshall EC, BonnMiller MO, Zvolensky M: Exploring the mediational role of coping motives for marijuana use in terms of the relation between anxiety sensitivity and marijuana dependence. Am J Addict 2010;19:277-282.

24 Hides L, Lubman DI, Cosgrave EM, Buckby JA, Killackey E, Yung AR: Motives for substance use among young people seeking mental health treatment. Early Interv Psychiatry 2008;2:188-194.

25 Bujarski SJ, Norberg MM, Copeland J: The association between distress tolerance and cannabis use-related problems: the mediating and moderating roles of coping motives and gender. Addict Behav 2012;37:11811184 . 
26 Agosti V, Nunes E, Levin F: Rates of psychiatric comorbidity among U.S. residents with lifetime cannabis dependence. Am J Drug Alcohol Abuse 2002;28:643-652.

-27 Lopez-Quintero C, Cobos JP, Hasin DS, Okuda M, Wang S, Grant BF, Blanco C: Probability and predictors of transition from first use to dependence on nicotine, alcohol, cannabis, and cocaine: results of the national epidemiologic survey on alcohol and related conditions (NESARC). Drug Alcohol Depend 2011;115: 120-130.

- 28 von Sydow K, Lieb R, Pfister H, Hofler M, Sonntag H, Wittchen HU: The natural course of cannabis use, abuse and dependence over four years: a longitudinal community study of adolescents and young adults. Drug Alcohol Depend 2001;64:347-361.

29 Wittchen HU, Frohlich C, Behrendt S, Gunther A, Rehm J, Zimmermann P, Lieb R, Perkonigg A: Cannabis use and cannabis use disorders and their relationship to mental disorders: a 10-year prospective-longitudinal community study in adolescents. Drug Alcohol Depend 2007;88(suppl 1):S60-S70.

- 30 Buckner JD, Schmidt NB, Lang AR, Small JW, Schlauch RC, Lewinsohn PM: Specificity of social anxiety disorder as a risk factor for alcohol and cannabis dependence. J Psychiatr Res 2008;42:230-239.

31 Harris T: Where Inner and Outer Worlds Meet: Psychosocial Research in the Tradition of George W Brown. London, Routledge, 2000.

- 32 Bruns C, Geist CS: Stressful life events and drug use among adolescents. J Human Stress 1984;10:135-139.

- 33 Hyman SM, Sinha R: Stress-related factors in cannabis use and misuse: implications for prevention and treatment. J Subst Abuse Treat 2009;36:400-413.

- 34 Windle M, Wiesner M: Trajectories of marijuana use from adolescence to young adulthood: predictors and outcomes. Dev Psychopathol 2004;16:1007-1027.

- 35 van der Pol P, Liebregts N, de Graaf R, Korf DJ, van den Brink W, van Laar M: The Dutch cannabis dependence (CanDep) study on the course of frequent cannabis use and dependence: objectives, methods and sample characteristics. Int J Methods Psychiatr Res 2011; 20:169-181.

- 36 Kessler RC, Ustun TB: The world mental health $(\mathrm{WMH})$ survey initiative version of the world health organization (WHO) composite international diagnostic interview (CIDI). Int J Methods Psychiatr Res 2004;13:93-121.

37 Sheehan DV: The Anxiety Disease. New York, Scribner, 1983.

38 Ware JE, Snow KK, Kosinski M, Gandek B: Health Survey Manual and Interpretation Guide. Boston, Health Institute, New England Medical Centre, 1993.

-39 Von Korff M, Crane PK, Alonso J, Vilagut G, Angermeyer MC, Bruffaerts R, de Girolamo G, Gureje O, de Graaf R, Huang Y, Iwata N,
Karam EG, Kovess V, Lara C, Levinson D, Posada-Villa J, Scott KM, Ormel J: Modified WHODAS-II provides valid measure of global disability but filter items increased skewness. J Clin Epidemiol 2008;61:1132-1143.

40 van der Pol P, Liebregts N, de Graaf R, Korf DJ, van den Brink W, van Laar M: Validation of selfreported cannabis dose and potency: an ecological study. Addiction 2013;108:1801-1808.

- 41 Simons JS, Gaher RM, Correia CJ, Hansen CL, Christopher MS: An affective-motivational model of marijuana and alcohol problems among college students. Psychol Addict Behav 2005; 19:326-334.

42 Bohn MJ, Babor TF, Kranzler HR: The alcohol use disorders identification test (AUDIT): validation of a screening instrument for use in medical settings. J Stud Alcohol 1995;56:423432.

43 Burling AS, Burling TA: A comparison of selfreport measures of nicotine dependence among male drug/alcohol-dependent cigarette smokers. Nicotine Tob Res 2003;5:625633.

44 Hovens JG, Wiersma JE, Giltay EJ, van Oppen P, Spinhoven P, Penninx BW, Zitman FG: Childhood life events and childhood trauma in adult patients with depressive, anxiety and comorbid disorders vs. controls. Acta Psychiatr Scand 2010;122:66-74.

45 Janssen I, Krabbendam L, Bak M, Hanssen M, Vollebergh W, de Graaf R, van Os J: Childhood abuse as a risk factor for psychotic experiences. Acta Psychiatr Scand 2004;109:3845.

46 Konings M, Stefanis N, Kuepper R, de Graaf R, ten Have M, van Os J, Bakoula C, Henquet $\mathrm{C}$ : Replication in two independent population-based samples that childhood maltreatment and cannabis use synergistically impact on psychosis risk. Psychol Med 2012;42:149159.

47 Zeisser C, Thompson K, Stockwell T, Duff C, Chow C, Vallance K, Ivsins A, Michelow W, Marsh D, Lucas P: A 'standard joint'? The role of quantity in predicting cannabis-related problems. Addict Res Theory 2011;20:82-92.

48 van der Pol P, Liebregts N, de Graaf R, Ten Have M, Korf DJ, van den Brink W, van Laar M: Mental health differences between frequent cannabis users with and without cannabis dependence and the general population. Addiction 2013;108:1459-1469.

49 Spinella MARC: Normative data and a short form of the Barratt impulsiveness scale. Int J Neurosci 2007;117:359-368.

50 Brugha $\mathrm{T}$, Bebbington $\mathrm{P}$, Tennant $\mathrm{C}$, Hurry J: The list of threatening experiences: a subset of 12 life event categories with considerable long-term contextual threat. Psychol Med 1985;15:189-194.

51 Hosmer DW, Lemeshow S, Sturdivant RX: Applied Logistic Regression, ed 3. Wiley, 2013, p 95.

52 Bonn-Miller MO, Zvolensky MJ: An evaluation of the nature of marijuana use and its mo- tives among young adult active users. Am J Addict 2009;18:409-416.

53 Chabrol H, Duconge E, Casas C, Roura C, Carey KB: Relations between cannabis use and dependence, motives for cannabis use and anxious, depressive and borderline symptomatology. Addict Behav 2005;30:829-840.

54 Fox CL, Towe SL, Stephens RS, Walker DD, Roffman RA: Motives for cannabis use in high-risk adolescent users. Psychol Addict Behav 2011;25:492-500.

55 Johnson K, Mullin JL, Marshall EC, BonnMiller MO, Zvolensky M: Exploring the mediational role of coping motives for marijuana use in terms of the relation between anxiety sensitivity and marijuana dependence. Am J Addict 2010;19:277-282.

56 Gates P, Copeland J, Swift W, Martin G: Barriers and facilitators to cannabis treatment. Drug Alcohol Rev 2012;31:311-319.

57 Agrawal A, Lynskey MT, Bucholz KK, Kapoor M, Almasy L, Dick DM, et al: DSM-5 cannabis use disorder: a phenotypic and genomic perspective. Drug Alcohol Depend 2014;134: 362-369.

58 Agrawal A, Lynskey MT: The genetic epidemiology of cannabis use, abuse and dependence. Addiction 2006;101:801-812.

59 Lynskey MT, Heath AC, Nelson EC, Bucholz KK, Madden PAF, Slutske WS, et al: Genetic and environmental contributions to cannabis dependence in a national young adult twin sample. Psychol Med 2002;32:195-207.

-60 Cousijn J, Goudriaan AE, Ridderinkhof KR, van den Brink W, Veltman DJ, Wiers RW: Neural responses associated with cue-reactivity in frequent cannabis users. Addict Biol 2013;18:570-580.

61 Henquet C, van Os J, Kuepper R, Delespaul P, Smits M, Campo JA, Myin-Germeys I: Psychosis reactivity to cannabis use in daily life: an experience sampling study. Br J Psychiatry 2010;196:447-453.

62 Larson R, Csikszentmihalyi M: The experience sampling method. New Dir Meth Soc Behav Sci 1983;15:41-56.

63 Liebregts N, van der Pol P, van Laar M, de Graaf R, van den Brink W, Korf DJ: The role of study and work in cannabis use and dependence trajectories among young adult frequent cannabis users. Front Psychiatry 2013; $4: 85$.

64 Liebregts N, van der Pol P, van Laar M, de Graaf R, van den Brink W, Korf DJ: The role of leisure and delinquency in frequent cannabis use and dependence trajectories among young adults. Int J Drug Policy 2015:26:143-152.

65 Rooke S, Copeland J, Norberg M, Hine D, McCambridge J: Effectiveness of a self-guided web-based cannabis treatment program: randomized controlled trial. J Med Internet Res 2013; 15:e26.

66 Tait RJ, Spijkerman R, Riper H: Internet and computer based interventions for cannabis use: a meta-analysis. Drug Alcohol Depend 2013;133:295-304. 